\title{
PENENTUAN FITUR WEBSITE BIDANG PARIWISATA DAN KEBUDAYAAN DENGAN METODE FEATURE- ORIENTED DOMAIN ANALYSIS (FODA)
}

\author{
M. Iqbal A. A. ${ }^{1}$, M. Reza Faisal'2, Irwan Budiman ${ }^{3}$ \\ 1,2,3 Prodi Ilmu Komputer FMIPA ULM \\ Jl. A. Yani Km 36 Banjarbaru, Kalimantan selatan \\ 1Email: uzanksalghifari@gmail.com
}

\begin{abstract}
Determination of the features in creating a tourism and cultures websites is required to find out which features are can be implemented. To help determination of the feature, we can use a domain analysis method Feature-Oriented Domain Analysis (FODA). The method has some step, starting with application review to three sample websites to take on the features. The next step are the context analysis to gain a structure diagram and a context diagram. The next step are the modeling domain which divided into two steps, first, features analysis to get the features of the web application through the features diagram with an explanation through domain terminology dictionary. The next step is the entity-relationship modeling by making entity-relationship diagrams for database creation. The final step are architecture modelings to create a domain architecture for application development that only focus on the features. The results from the feature analysis get 38 mandatory features which be implemented on a web application for tourism and culture.
\end{abstract}

Keywords: Tourism, Culture, Website, Features, FODA

\begin{abstract}
Abstrak
Penentuan fitur dalam membuat website bidang pariwisata dan kebudayaan dibutuhkan untuk mengetahui fitur yang bisa diimplementasikan. Untuk membantu menentukan fitur tersebut, digunakan analisis domain dengan metode Feature-Oriented Domain Analysis (FODA). Metode tersebut mempunyai tahapan dimulai dari tinjauan aplikasi terhadap ketiga website sebagai sampel untuk mengambil fitur. Selanjutnya tahapan analisis konteks yang mendapatkan diagram struktur dan diagram konteks. Berikutnya tahapan pemodelan domain yang dibagi dua langkah yaitu analisis fitur untuk mendapatkan fitur-fitur pada aplikasi web melalui diagram fitur dengan penjelasan melalui kamus terminologi domain. Langkah berikutnya adalah pemodelan entity-relationship dengan membuat diagram entity-relationship untuk pembuatan database. Terakhir, pemodelan arsitektur dengan membuat arsitektur domain untuk pengembangan aplikasi yang hanya fokus pada fitur. Hasil dari analisis fitur adalah didapatkan sebanyak 38 fitur mandatory yang berarti fitur tersebut wajib diimplementasikan dalam aplikasi web untuk pariwisata dan kebudayaan.
\end{abstract}

Kata kunci: Pariwisata, Kebudayaan, Website, Fitur, FODA 


\section{PENDAHULUAN}

Pariwisata merupakan perjalanan yang dilakukan oleh seseorang/kelompok untuk sementara waktu ke suatu tempat dengan tujuan rekreasi/tamasya. Belakangan ini perjalanan pariwisata menjadi trending topic bagi semua orang di dunia terutama di Indonesia juga. Hal ini didorong oleh tersedianya informasi tempat wisata yang bisa diakses oleh siapa saja dan dimana saja lewat internet.

Salah satu media informasi di internet yang sering dikunjungi oleh wisatawan untuk mendapatkan gambaran perjalanan liburan yaitu website. Hal ini dijelaskan oleh pihak VISA melalui surveinya bertajuk Visa Global Travel Intentions Study 2013, bahwa wisatawan sebanyak 71\% menyatakan sumber pencarian informasi perjalanan didapatkan dari digital (seperti website terutama website review perjalanan, pemesanan akomodasi lewat online, pemesanan tiket transportasi lewat online, social media dan sejenisnya).

Salah satu tahapan dalam pembuatan perangkat lunak dengan menggunakan metode Waterfall yaitu tahapan spesifikasi kebutuhan pengguna yang dimana pada langkah tersebut dilakukan survey dan wawancara terhadap orang atau pihak ahli yang memberikan referensi sehingga menghasilkan informasi berupa penentuan fitur-fitur yang akan dijadikan perangkat lunak. Hal inilah yang biasa dilakukan dalam pembuatan perangkat lunak seperti pembuatan perangkat lunak bidang pariwisata.

Pembuatan perangkat lunak akan menemukan hambatan dalam penentuan fitur-fitur dikarenakan tidak adanya orang atau pihak ahli yang memberikan informasi sebagai referensi pembuatan perangkat lunak. Maka ada cara lain dalam penentuan fitur-fitur pada perangkat lunak yaitu dengan melakukan analisis dan eksplorasi fitur-fitur pada perangkat lunak yang sudah ada. Solusi inilah yang dilakukan dalam pembuatan perangkat lunak berupa website pariwisata dengan menggunakan metode analisis dan eksplorasi fitur-fitur pada website pariwisata yang sudah ada.

Penentuan fitur pada model website bidang pariwisata dan kebudayaan menggunakan metode yang telah ada digunakan dalam menganalisis dan mengeksplorasi fitur pada website yaitu metode Feature-Oriented Domain Analysis (FODA). Metode FODA melakukan analisis terhadap website dengan penekanan lebih pada identifikasi fitur-fitur didalam sistem tersebut. Memilih metode ini karena framework yang cukup lengkap dalam pemetaan struktur, konteks, fitur, keterkaitan/relasi hingga arsitektur domain. Hasil dari penelitian ini adalah mendapatkan fitur-fitur untuk menentukan fitur model website pariwisata dan kebudayaan. Dengan model website tersebut dapat dijadikan panduan dalam pembuatan website bidang pariwisata dan kebudayaan.

\section{METODE PENELITIAN}

\subsection{Identifikasi Kebutuhan}

Sebelum memulai penelitian maka dilakukanlah identifikasi kebutuhan yang dibagi dua tahap yaitu studi literatur dan pengumpulan data. Studi literatur dilakukan dengan mengumpulkan kajian berupa referensi untuk meneliti seperti jurnal, buku, makalah dan lain-lain. Untuk pengumpulan data dilakukan dengan 
mencari website pariwisata dan kebudayaan berbahasa Indonesia, milik pemerintah, dan dalam keadaan aktif.

\subsection{Analisis dengan Feature-Oriented Domain Analysis (FODA)}

Metode Feature-Oriented Domain Analysis (FODA) mengenalkan sebuah konsep fitur model untuk rekayasa domain dalam upaya untuk mewakili fitur standar dalam keluarga sistem dalam domain serta hubungan antara fitur tersebut. Tujuannya untuk menciptakan model domain yang mewakili keluarga system yang kemudian dapat disempurnakan menjadi sistem yang diinginkan.

Metode FODA memiliki tiga tahapan, yaitu context analysis (analisis konteks), domain modelling (pemodelan domain), dan architecture modelling (pemodelan arsitektur). Tahap analisis konteks bertujuan untuk mendapatkan informasi dan mengidentifikasi entitas-entitas yang membentuk aplikasi pada domain terkait. Tahap pemodelan domain bertujuan untuk mengidentifikasi relasi dan kebergantungan entitas-entitas yang pada ada pada domain terkait, sedangkan tahap pemodelan arsitektur bertujuan untuk menyediakan perangkat lunak sebagai solusi dari masalah yang didefinisikan dalam tahap sebelumnya. [4]

\subsubsection{Tinjauan Aplikasi}

Pengumpulan data berupa website bidang pariwisata dan kebudayaan milik pemerintah dalam keadaan aktif mendapatkan tiga buah aplikasi web yaitu www.indonesia.travel (milik Kementerian Pariwisata Republik Indonesia), www.jakarta-tourism.go.id (milik Pemerintah Provinsi DKI Jakarta), dan www.kepri.travel (milik Pemerintah Provinsi Kepulauan Riau).

Ketiga website tersebut melalui tahapan tinjauan aplikasi yaitu analisis dan identifikasi untuk mendapatkan informasi umum dan fitur-fitur yang terdapat pada aplikasi web. Dari ketiga website, fitur-fitur yang didapatkan dirangkum untuk dijadikan fitur yang akan dianalisis pada tahap selanjutnya dalam analisis domain. Fitur tersebut dapat dilihat pada daftar fitur aplikasi sebanyak 11 fitur dari 57 buah yang didapatkan sebagai berikut:

Tabel 1. Daftar Fitur Aplikasi

\begin{tabular}{|c|c|c|c|c|}
\hline No & Fitur & Indonesia.Travel & $\begin{array}{c}\text { Jakarta- } \\
\text { Tourism.go.id }\end{array}$ & Kepri.Travel \\
\hline 1 & $\begin{array}{l}\text { Memilih fitur } \\
\text { bahasa }\end{array}$ & $\checkmark$ & $\checkmark$ & - \\
\hline 2 & $\begin{array}{l}\text { Melakukan } \\
\text { pencarian }\end{array}$ & $\checkmark$ & $\checkmark$ & $\checkmark$ \\
\hline 3 & $\begin{array}{l}\text { Melakukan } \\
\text { registrasi sebagai } \\
\text { anggota }\end{array}$ & $\checkmark$ & - & - \\
\hline 4 & $\begin{array}{l}\text { Menampilkan } \\
\text { informasi melalui } \\
\text { slider/carousel }\end{array}$ & $\checkmark$ & - & $\checkmark$ \\
\hline 5 & $\begin{array}{l}\text { Menampilkan } \\
\text { informasi melalui } \\
\text { banner }\end{array}$ & $\checkmark$ & $\checkmark$ & $\checkmark$ \\
\hline
\end{tabular}




\begin{tabular}{|c|c|c|c|c|}
\hline No & Fitur & Indonesia.Travel & $\begin{array}{c}\text { Jakarta- } \\
\text { Tourism.go.id }\end{array}$ & Kepri.Travel \\
\hline 6 & $\begin{array}{l}\text { Menampilkan } \\
\text { Navigation on Top } \\
\text { melalui menu bar }\end{array}$ & $\checkmark$ & $\checkmark$ & $\checkmark$ \\
\hline 7 & $\begin{array}{l}\text { Menampilkan } \\
\text { informasi melalui } \\
\text { featured post }\end{array}$ & $\checkmark$ & $\checkmark$ & $\checkmark$ \\
\hline 8 & $\begin{array}{l}\text { Menampilkan } \\
\text { daftar event }\end{array}$ & $\checkmark$ & $\checkmark$ & - \\
\hline 9 & $\begin{array}{l}\text { Menampilkan } \\
\text { event berdasarkan } \\
\text { kategori }\end{array}$ & $\checkmark$ & $\checkmark$ & - \\
\hline 10 & $\begin{array}{l}\text { Menampilkan } \\
\text { daftar event } \\
\text { berdasarkan } \\
\text { urutan dari } \\
\text { terlama ke terbaru }\end{array}$ & $\checkmark$ & $\checkmark$ & - \\
\hline 11 & 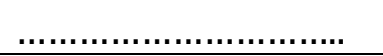 & $\ldots$ & .... & $\ldots$ \\
\hline
\end{tabular}

Pada tabel, fitur tersebut didapatkan dari ketiga website sampel, setiap fitur diberi tanda apakah ada di setiap aplikasi web atau tidak ada. Jika fitur tersebut ada dalam ketiga website, maka dalam tahapan analisis fitur, fitur tersebut bersifat mandatory. Jika fitur hanya ada dalam dua website, maka fitur tersebut bisa bersifat optional, $O R$, dan alternative. Jika fitur hanya satu dalam website, maka fitur tersebut optional.

\subsubsection{Analisis Konteks}

Analisis konteks bertujuan untuk mengidentifikasi lingkup, batasan, dan relasi yang ada pada entitas-entitas domain terkait. Dalam tahap ini menampilkan hasil akhir yaitu model konteks terdiri dari diagram struktur dan diagram konteks (atau data-flow diagram). Dalam analisis konteks juga dihasilkan pengamatan terhadap ketiga aplikasi web sampel, yaitu berupa karakteristik dalam website yang terbagi menjadi Berita, Event, dan Wisata. Wisata juga terbagi lagi tiga entitas yaitu Tujuan Wisata, Objek Wisata, dan Panduan Wisatawan.

Tujuan pembuatan diagram untuk menggambarkan secara jelas apa yang terjadi dalam ruang lingkup domain yang dianalisis. Diagram struktur dibuat dimulai dengan menentukan domain pariwisata dan kebudayaan ditempatkan diantara level tinggi dan rendah dalam struktur yang menandakan sebagai lingkup keseluruhan domain. Diagram konteks dibuat dimulai dengan mengeksplorasi website yang menjadi aplikasi yang dipilih untuk membuat domain pariwisata dan kebudayaan, eksplorasi yang dilakukan untuk mengetahui masukan dan keluaran. Website yang mewakili domain tersebut dianalisis berupa aliran data yang dimiliki. Berikut ini diagram struktur yang dihasilkan dari analisis konteks : 


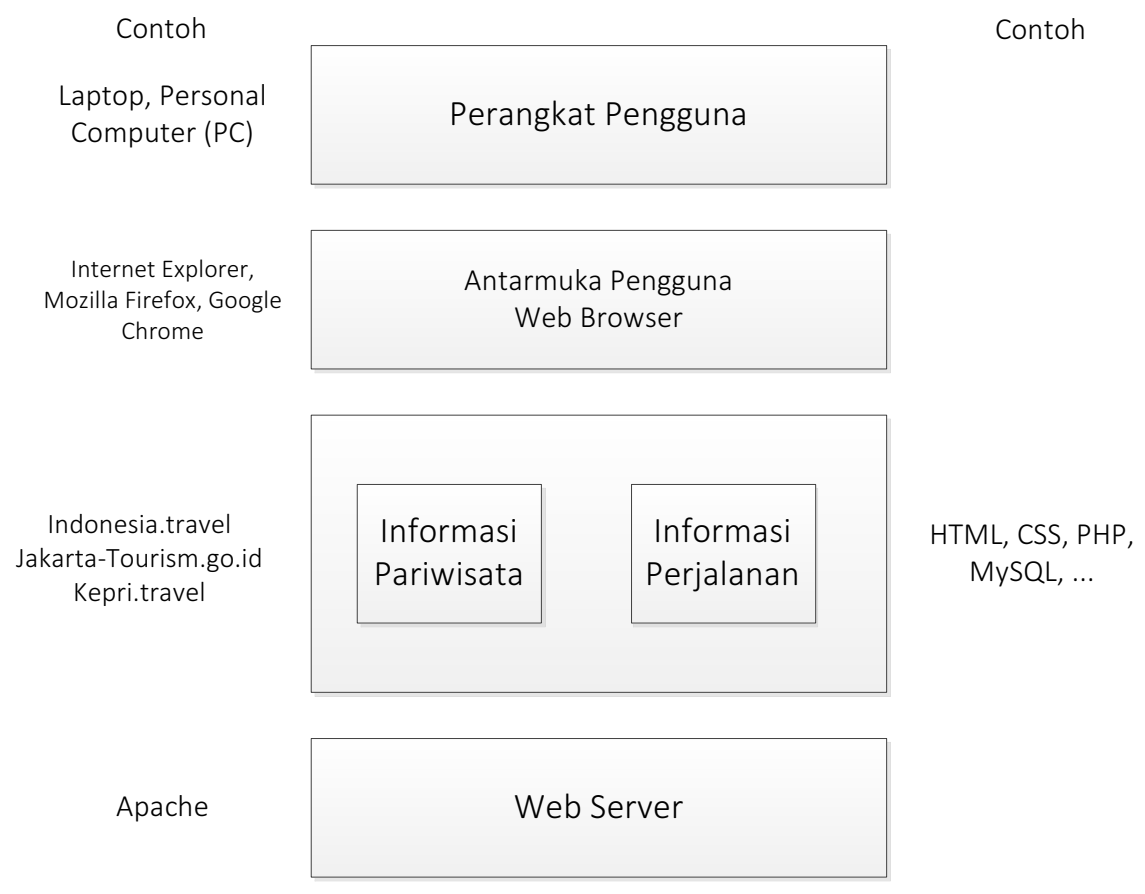

Gambar 1. Diagram struktur

Berikut ini diagram konteks yang dihasilkan dari analisis konteks :

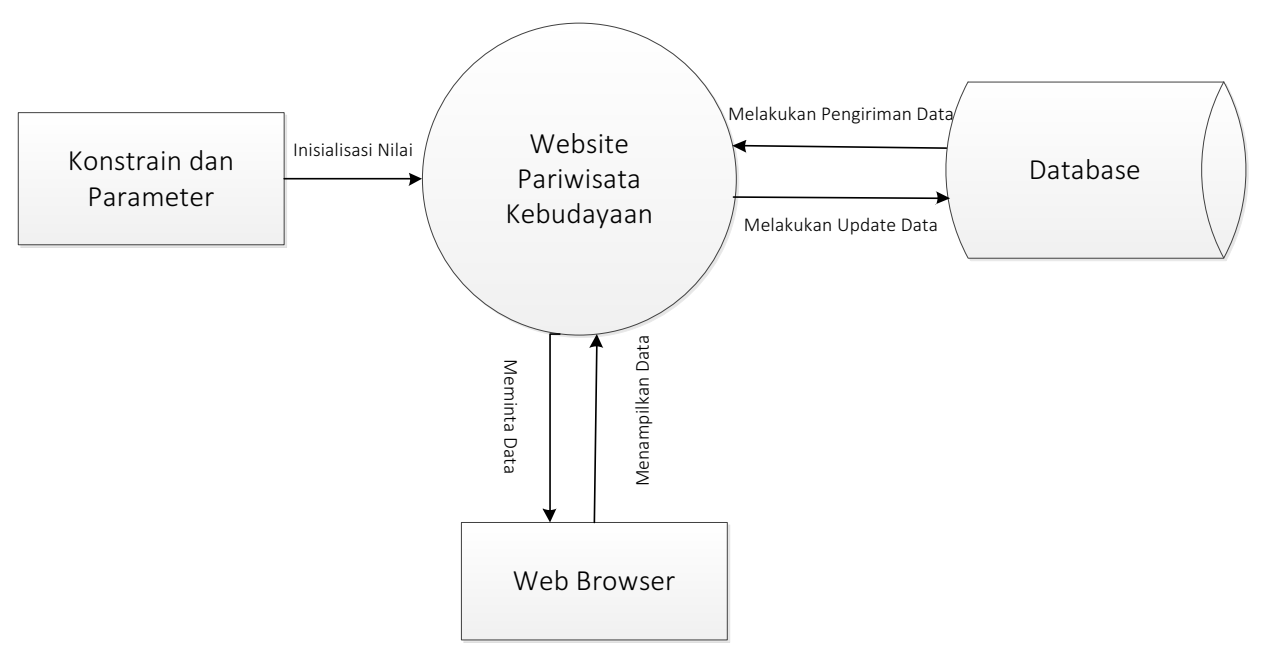

Gambar 2. Diagram konteks

\subsubsection{Pemodelan Domain}

Pemodelan domain mempunyai fungsi untuk menganalisa kesamaan dan perbedaan masing-masing entitas pada website bidang pariwisata dan kebudayaan. Dalam penelitian ini, tahapan pemodelan domain dibagi dua langkah yaitu analisis fitur dan pemodelan entity-relationship.

a. Analisis Fitur

Analisis fitur bertujuan untuk menemukan kebutuhan fitur dari website pariwisata dan kebudayaan. Kebutuhan tersebut dilakukan dengan 
menggunakan analisis fitur melalui gambaran diagram fitur dan kamus terminologi domain. Diagram fitur adalah diagram hirarki bentuk pohon yang menghubungkan antara fitur dengan sub-fitur.

Dalam diagram fitur ada 4 simbol yang memberikan gambaran hubungan antara fitur dengan sub-fitur, yaitu:

1) Mandatory merupakan simbol yang ditunjukkan oleh garis dengan kepala bulat diarsir. Mandatory menunjukkan bahwa sub-fitur harus diimplementasikan dalam domain.

2) Optional merupakan simbol yang ditunjukkan oleh garis dengan kepala bulat yang tidak diarsir. Optional menunjukkan bahwa sub-fitur tidak harus diimplementasikan dalam domain.

3) $O R$ merupakan simbol yang ditunjukkan oleh garis busur yang diarsir. $O R$ menunjukkan bahwa harus dipilih salah satu sub-fitur untuk diimplementasikan dalam domain.

4) Alternative merupakan simbol yang ditunjukkan oleh garis busur yang tidak diarsir. Alternative menunjukkan bahwa bisa dipilih salah satu subfitur untuk diimplementasikan dalam domain.

Berikut ini diagram fitur yang menunjukkan fitur utama dalam website pariwisata dan kebudayaan yang didapatkan dalam analisis :

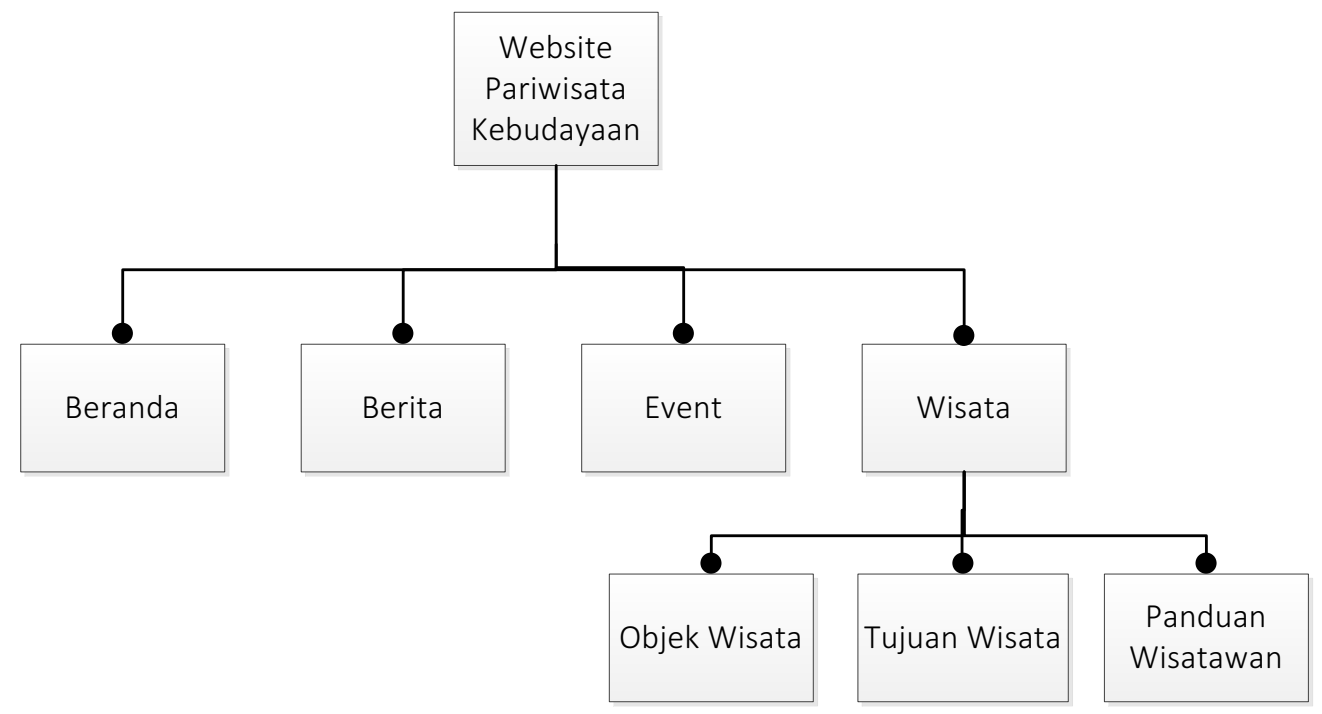

Gambar 3. Diagram fitur utama website pariwisata dan kebudayaan

Dalam fitur utama website terdapat subfitur-subfitur yang dibuatkan diagram fitur. Dalam penelitian ini, terdapat 6 buah diagram fitur yaitu diagram fitur Beranda, Berita, Event, Objek Wisata, Tujuan Wisata dan Panduan Wisatawan. Setiap diagram fitur tersebut ada sub-fitur dan masing-masing punya simbol fitur seperti mandatory, optional, or, dan alternative. Berikut ini salah satu diagram fitur dalam penelitian yaitu diagram fitur objek wisata : 


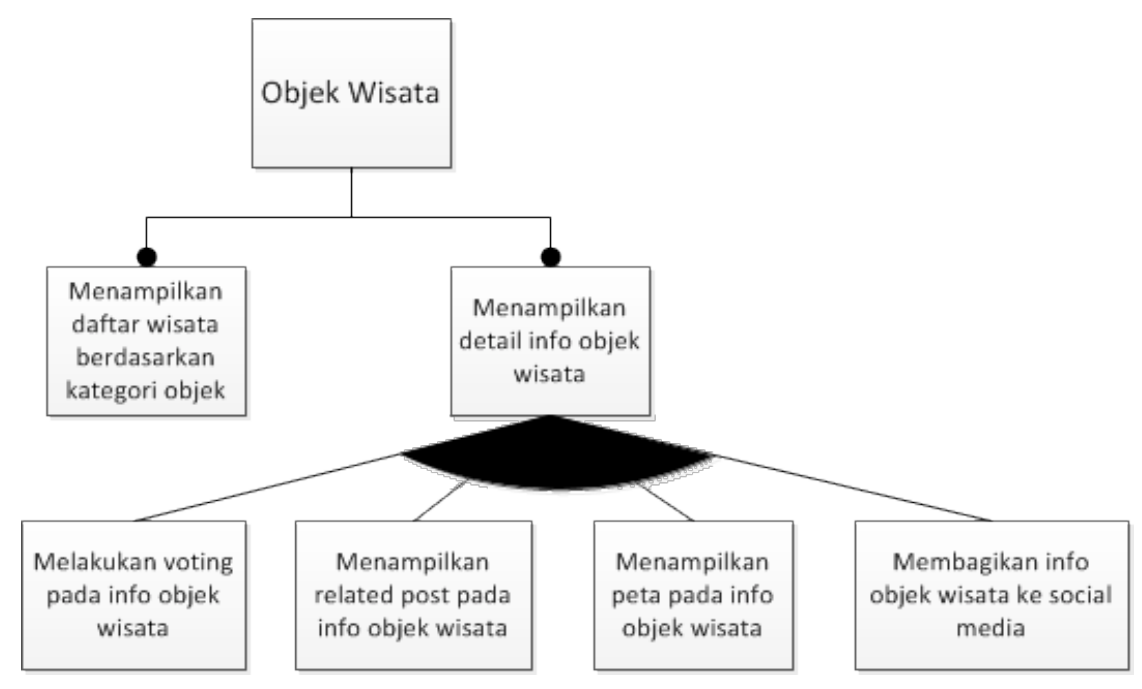

Gambar 4. Diagram Fitur Objek Wisata

b. Pemodelan entity-relationship

Pemodelan entity-relationship dibuat untuk menemukan hubungan antara entitas-entitas yaitu fitur pada domain model website bidang pariwisata dan kebudayaan. Hasil yang didapatkan dari tahap ini yaitu diagram entityrelationship, dari diagram inilah yang akan dijadikan panduan untuk pembuatan database model domain pada aplikasi web. Berikut diagram entityrelationship:

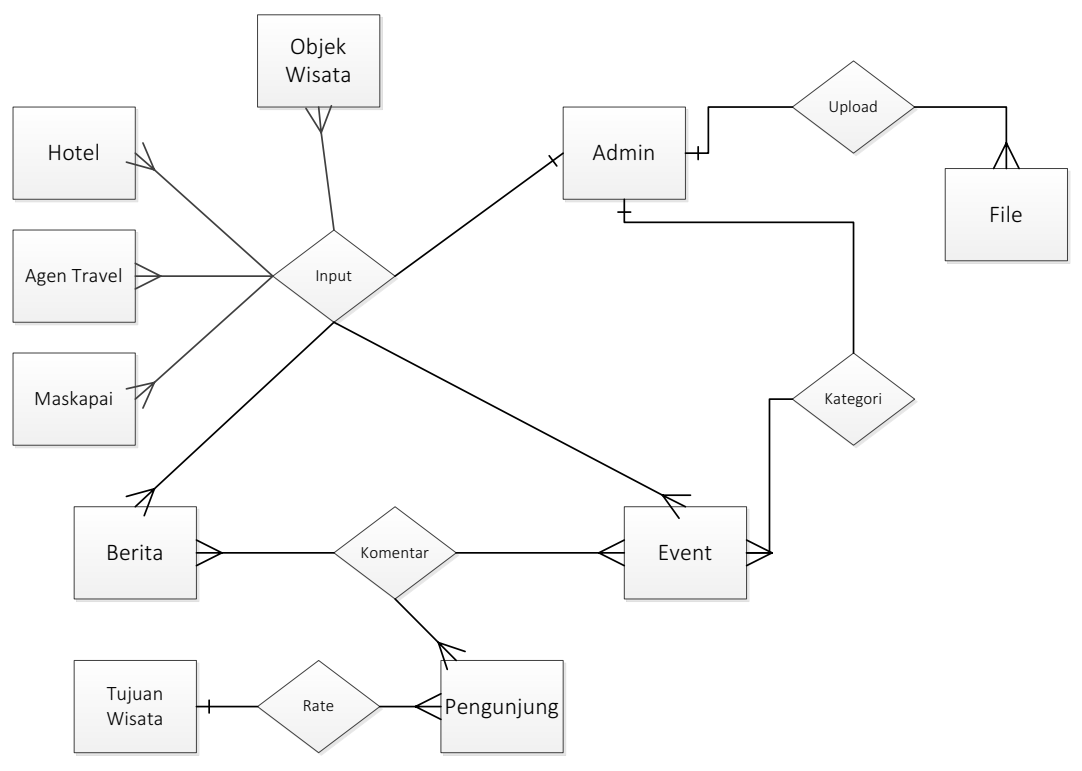

Gambar 5. Diagram entity-relationship

\subsubsection{Pemodelan Arsitektur}

Tahapan terakhir dalam menggunakan metode FODA yaitu membuat pemodelan arsitektur dengan menghasilkan arsitektur untuk model domain website pariwisata dan kebudayaan. Arsitektur digunakan untuk pengembangan 
aplikasi web yang dibuat kedepannya yang fokus hanya pada penambahan fitur yang disesuaikan kebutuhan domain. Berikut ini model arsitektur yang didapatkan dari fitur utama pada analisis fitur :

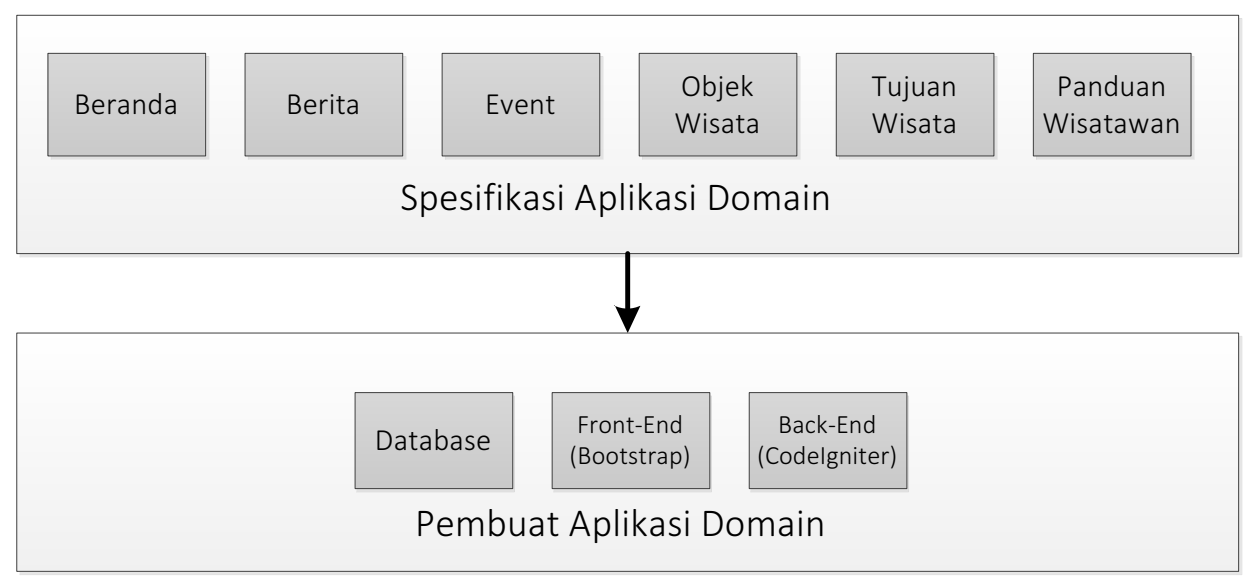

Gambar 6. Model Arsitektur

\section{HASIL DAN PEMBAHASAN}

\subsection{Hasil}

Penentuan fitur untuk website bidang pariwisata dan kebudayaan dalam penelitian ini menggunakan metode Feature-Oriented Domain Analysis (FODA). Metode tersebutlah yang dapat menyelesaikan perumusan masalah yaitu mendapatkan fitur untuk diimplementasikan menjadikan website.

Analisis fitur dengan menggunakan metode FODA menghasilkan banyak fitur yang tersaji melalui diagram fitur. Hasil dari langkah analisis fitur menghasilkan diagram fitur yang menghubungkan antara fitur dengan sub-fitur. Sehingga fitur untuk website pariwisata dan kebudayaan terdiri dari sub-fitur Beranda, Berita, Event dan Wisata. Masing-masing dari sub-fitur tersebut menghasilkan diagram fitur yang menerangkan fitur yang bersifat mandatory, optional, or dan alternative.

a. Sub-fitur Beranda menghasilkan diagram fitur dengan rincian 10 fitur mandatory, 5 fitur optional dan 7 fitur or.

b. Sub-fitur Berita menghasilkan diagram fitur dengan rincian 3 fitur mandatory, 2 fitur optional dan 3 fitur alternative.

c. Sub-fitur Event menghasilkan diagram fitur dengan rincian 5 fitur mandatory, 1 fitur optional, dan 3 fitur alternative.

d. Sub-fitur Wisata dibagi lagi menjadi 3 sub-fitur yaitu Tujuan Wisata, Objek Wisata dan Panduan Wisatawan.

1) Tujuan Wisata menghasilkan diagram fitur dengan rincian 6 fitur mandatory dan 3 fitur optional.

2) Objek Wisata menghasilkan diagram fitur dengan rincian 2 fitur mandatory dan 4 fitur or.

3) Panduan Wisatawan menghasilkan diagram fitur dengan rincian 13 fitur mandatory dan 4 fitur optional. 
Untuk menjelaskan tentang isi diagram fitur maka dibuatlah kamus terminologi domain dalam bentuk tabel untuk memberikan pengetahuan umum tentang diagram fitur beserta sub-fiturnya.

Sedangkan untuk diimplementasikan dalam website pariwisata dan kebudayaan maka dipilihlah fitur mandatory yang bersifat harus diimplementasikan dalam domain yaitu website.

Berikut ini fitur mandatory untuk website:

Tabel 1. Daftar Fitur Fungsional yang ditampilkan

\begin{tabular}{|c|c|}
\hline No & Nama Fitur \\
\hline F.01 & Memilih Fitur Bahasa \\
\hline F.02 & Melakukan Pencarian \\
\hline F.03 & $\begin{array}{l}\text { Menampilkan Navigation on Top melalui } \\
\text { Menu Bar }\end{array}$ \\
\hline F.04 & Menampilkan Informasi \\
\hline F.05 & $\begin{array}{l}\text { Menampilkan } \\
\text { slider/carousel }\end{array} \quad$ informasi melalui \\
\hline F.06 & Menampilkan informasi melalui banner \\
\hline F.07 & $\begin{array}{l}\text { Menampilkan berita dan video melalui } \\
\text { featured post. }\end{array}$ \\
\hline F.08 & Menampilkan kontak \\
\hline F.09 & Menampilkan alamat pada kontak \\
\hline F.10 & $\begin{array}{l}\text { Melakukan pengiriman pesan melalui form } \\
\text { kontak }\end{array}$ \\
\hline F.11 & Menampilkan daftar berita \\
\hline F.12 & $\begin{array}{l}\text { Menampilkan daftar berita berdasarkan } \\
\text { urutan dari terlama ke terbaru }\end{array}$ \\
\hline F.13 & Menampilkan detail berita. \\
\hline F.14 & Menampilkan daftar event \\
\hline F.15 & $\begin{array}{l}\text { Menampilkan daftar event berdasarkan } \\
\text { kategori }\end{array}$ \\
\hline F.16 & $\begin{array}{l}\text { Menampilkan daftar event berdasarkan } \\
\text { urutan dari terlama ke terbaru }\end{array}$ \\
\hline F.17 & $\begin{array}{l}\text { Menampilkan daftar event berdasarkan } \\
\text { waktu }\end{array}$ \\
\hline F.18 & Menampilkan detail event yang dipilih \\
\hline F.19 & Menampilkan daftar tujuan wisata \\
\hline F.20 & $\begin{array}{l}\text { Menampilkan daftar tujuan } \\
\text { berdasarkan kategori lokasi }\end{array}$ \\
\hline
\end{tabular}

\begin{tabular}{ll}
\hline No & Nama Fitur \\
\hline F.21 & $\begin{array}{l}\text { Menampilkan detail info tujuan } \\
\text { wisata } \\
\text { Felakukan voting pada info tujuan }\end{array}$ \\
$\begin{array}{l}\text { wisata } \\
\text { Fembagikan info tujuan wisata ke } \\
\text { social media } \\
\text { Fenampilkan peta pada info tujuan } \\
\text { wisata }\end{array}$
\end{tabular}

F.25 Menampilkan daftar wisata

F.26 Menampilkan detail info objek wisata

F.27 Menampilkan daftar fasilitas pendukung wisata

F.28 Menampilkan daftar agen travel

F.29 Menampilkan daftar hotel

F.30 Menampilkan daftar maskapai penerbangan

F.31 Menampilkan daftar download

F.32 Menampilkan info daerah

F.33 Menampilkan info tentang sejarah \& budaya daerah yang dikenalkan

F.34 Menampilkan info tentang daerah yang dikenalkan

F.35 Menampilkan informasi umum

F.36 Menampilkan pusat informasi

F.37 Menampilkan info berupa dokumen perjalanan wisata

F.38 Menampilkan tips perjalanan di daerah

\subsection{Pembahasan}

Penelitian menggunakan metode Feature-Oriented Domain Analysis (FODA) mempunyai tahapan dimulai dari tinjauan aplikasi dengan mengumpulkan ketiga aplikasi website pariwisata dan kebudayaan sebagai sampel. Selanjutnya tahapan analisis konteks yang menghasilkan diagram struktur dan diagram konteks. 
Tahapan berikutnya adalah fitur yang didapatkan dalam ketiga aplikasi website sampel masuk analisis pada pemodelan domain yaitu analisis fitur dengan penggambaran melalui diagram fitur dan penjelasan melalui kamus terminologi domain. Serta tahapan kedua dalam pemodelan domain yaitu pemodelan entityrelationship menghasilkan diagram entity-relationship yang mengetahui hubungan antara fitur dengan domain. Terakhir, pemodelan arsitektur menghasilkan arsitektur untuk menjelaskan fitur utama yang didapatkan pada analisi fitur.

Jumlah fitur yang didapatkan dari hasil analisis domain menggunakan metode Feature-Oriented Domain Analysis (FODA) sebanyak 64 fitur yang didapatkan pada tahapan analisis fitur. Dari fitur sebanyak itulah ditentukan 38 fitur mandatory (fitur yang harus diimplementasikan), 34 fitur admin (didapatkan dari kesesuaian dengan fitur mandatory untuk ditampilkan ke pengunjung), serta 6 fitur gabungan $O R$ ( fitur yang harus dipilih salah satu untuk diimplementasikan) dan alternative (fitur yang bisa dipilih salah satu untuk diimplementasikan).

Fitur tersebut dibagi dalam entitas pada domain yaitu website pariwisata dan kebudayaan. Entitas ada 6 bagian yaitu Beranda, Berita, Event, Objek Wisata, Tujuan Wisata, dan Panduan Wisatawan. Fitur-fitur itulah yang harus diimplementasikan dan dibuat ketika programmer membuat website pariwisata dan kebudayaan nantinya. Oleh karena itu, penelitian ini telah berhasil menentukan dan mendapatkan fitur-fitur untuk website pariwisata dan kebudayaan.

\section{SIMPULAN}

Dari hasil penelitian dan pengamatan yang telah dibuat, maka dapat diperoleh kesimpulan yaitu penentuan fitur untuk diimplementasikan menjadi website bidang pariwisata dan kebudayaan didapatkan sebanyak 38 fitur mandatory yang dibagi pada entitas Beranda, Berita, Event, Tujuan Wisata, Objek Wisata, serta Panduan Wisatawan. Fitur yang didapatkan itulah yang dijadikan panduan dalam pembuatan website bidang pariwisata dan kebudayaan nantinya.

\section{DAFTAR PUSTAKA}

[1] Andhika, S., Gonydjaja, R. Implementasi Bahasa Domain yang Spesifika pada Perangkat Lunak Trafficsqueezer Menggunakan Metode FODA. Jurusan Teknik Informatika, Fakultas Teknologi Industri, Universitas Gunadarma, Depok.

[2] Barman, A.A, et al. 2009. Feature-Oriented Domain Analysis (FODA) Fantasy Football Web Software. New Jersey: New Jersey Institute of Technology, Computer Science Department , 2009.

[4] Kang, K. C., Cohen, S.G., Hess, J.A., Novak, W.E., Peterson, A.S. 1990. Feature Oriented Domain Analysis (FODA) Feasibility Study. Software Engineering Institute, Universitas Carnegie Mellon, Pittsburgh, Pennsylvania.

[5] Murtadho, A., Shihab, M.R. 2011. Analisis Situs E-Tourism Indonesia: Studi Terhadap Persebaran Geografis, Pengklasifikasian Situs serta Pemanfaatan Fungsi dan Fitur. Journal of Information Systems. 7: 13-25. 